\title{
Infliximab plus methotrexate is superior to methotrexate alone in the treatment of psoriatic arthritis in methotrexate-naive patients: the RESPOND study
}

\author{
Asta Baranauskaite, ${ }^{1}$ Helena Raffayová, ${ }^{2}$ NV Kungurov, ${ }^{3}$ Anna Kubanova, ${ }^{4}$ Algirdas \\ Venalis, ${ }^{5}$ Laszlo Helmle, ${ }^{6}$ Shankar Srinivasan, ${ }^{7}$ Evgeny Nasonov, ${ }^{8}$ Nathan Vastesaeger ${ }^{9}$; \\ RESPOND investigators*
}

${ }^{1}$ Kaunas Medical University Hospital, Kaunas, Lithuania ${ }^{2}$ National Institute for Rheumatology Diseases, Piestany, Slovakia

${ }^{3}$ Urals Dermatovenereology Institute, Yekaterinburg, Russia ${ }^{4}$ Central DermatoVenereology Institute, Moscow, Russia ${ }^{5}$ Vilnius University Hospital, Vilnius, Lithuania

${ }^{6} \mathrm{MSD}$, Budapest, Hungary

${ }^{7}$ Merck \& Co, Inc, Kenilworth,

New Jersey, USA

${ }^{8}$ Central Rheumatology Institute, Moscow, Russia

${ }^{9} \mathrm{MSD}$, Brussels, Belgium

\section{Correspondence to}

Nathan Vastesaeger Department of Immunology, MSD, Rue de Stalle 73, B-1180 Brussels, Belgium; nathan.vastesaeger@merck.com

*See list of RESPOND investigators at the end of the paper.

Accepted 27 August 2011 Published Online First 12 October 2011
ABSTRACT

Objective To compare the efficacy and safety of treatment with infliximab plus methotrexate with methotrexate alone in methotrexate-naive patients with active psoriatic arthritis (PsA).

Methods In this open-label study, patients 18 years and older with active PsA who were naive to methotrexate and not receiving disease-modifying therapy $(N=115)$ were randomly assigned $(1: 1)$ to receive either infliximab ( $5 \mathrm{mg} / \mathrm{kg}$ ) at weeks 0, 2, 6 and 14 plus methotrexate (15 mg/week); or methotrexate (15 mg/week) alone. The primary assessment was American College of Rheumatology (ACR) 20 response at week 16. Secondary outcome measures included psoriasis area and severity index (PASI), disease activity score in 28 joints (DAS28) and dactylitis and enthesitis assessments.

Results At week 16, 86.3\% of patients receiving infliximab plus methotrexate and $66.7 \%$ of those receiving methotrexate alone achieved an ACR20 response $(p<0.02)$. Of patients whose baseline PASI was 2.5 or greater, $97.1 \%$ receiving infliximab plus methotrexate compared with $54.3 \%$ receiving methotrexate alone experienced a $75 \%$ or greater improvement in PASI $(p<0.0001)$. Improvements in C-reactive protein levels, DAS28 response and remission rates, dactylitis, fatigue and morning stiffness duration were also significantly greater in the group receiving infliximab. In the infliximab plus methotrexate group, 46\% (26/57) had treatmentrelated adverse events (AE) and two patients had serious $A E$, compared with $24 \%$ with $A E(13 / 54)$ and no serious $A E$ in the methotrexate-alone group.

Conclusions Treatment with infliximab plus methotrexate in methotrexate-naive patients with active PsA demonstrated significantly greater ACR20 response rates and PASI75 improvement compared with methotrexate alone and was generally well tolerated. This trial is registered in the US National Institutes of Health clinicaltrials.gov database, identifier NCT00367237.

Psoriatic arthritis (PsA) is an inflammatory arthropathy associated with skin psoriasis. ${ }^{1}$ The estimated prevalence of psoriasis is $1-3 \%$ of the population, and the reported prevalence of PsA among patients with psoriasis ranges from $6 \%$ to $48 \% .{ }^{1-4}$ PsA has a substantial impact on patients' lives ${ }^{15-9}$ and is associated with persistent inflammation, 610 progressive joint damage leading to functional disability $^{510}$ and reduced life expectancy. ${ }^{17}$

Methotrexate is often used as the primary treat ment for PsA, despite a paucity of evidence demonstrating its clinical benefit. ${ }^{10-12}$ In fact, to date, only two randomised controlled trials of methotrexate in PsA have been published, and neither was sufficiently powered to assess the clinical benefit. ${ }^{13}$ 14 Black et al ${ }^{13}$ demonstrated in 21 patients with long-term disease that methotrexate injections at 10-day intervals provided some improvement in joint symptoms and decreased area of skin involvement versus placebo. Willkens et a ${ }^{14}$ compared oral pulse methotrexate therapy with placebo in 37 PsA patients with long-term disease over 12 weeks and found methotrexate to be statistically superior to placebo only in physician assessment of arthritis activity and in the reduction of surface area affected by psoriasis.

Tumour necrosis factor (TNF) inhibitors are an established treatment for both skin and locomotor system manifestations of PsA. ${ }^{10}{ }^{15-20}$ The efficacy of infliximab for reducing symptoms and halting radiographic progression was first established in the placebo-controlled Infliximab Multinational Psoriatic Arthritis Controlled Trial (IMPACT) and IMPACT 2 studies. ${ }^{21-24}$ To date, evidence to support any superiority of TNF inhibitors plus methotrexate over methotrexate alone is lacking. ${ }^{10} 12$

The present open-label study compared the efficacy and safety of infliximab in combination with methotrexate to methotrexate alone in methotrexate-naive subjects with active polyarticular PsA.

\section{METHODS \\ Patient population}

Enrolled patients were 18 years or older, rheumatoid factor negative, and had psoriasis in combination with peripheral articular disease with at least one of the following four characteristics for 3 or more months before screening: distal interphalangeal joint involvement; polyarticular arthritis in the absence of rheumatoid nodules; arthritis mutilans; or asymmetric peripheral arthritis. Active disease was defined as the presence of five or more swollen joints, five or more tender joints and at least 
one of the following: erythrocyte sedimentation rate (ESR) 28 $\mathrm{mm} / \mathrm{h}$ or greater; C-reactive protein (CRP) $15 \mathrm{mg} / \mathrm{l}$ or greater, or morning stiffness for $45 \mathrm{~min}$ or more. Patients were naive to methotrexate, infliximab and other biological agents, and those with known contraindications to methotrexate or infliximab were excluded from participation. Leflunomide and other disease-modifying antirheumatic drugs (DMARD) could not be used within 6 months or 12 weeks, respectively, before study screening. Tacrolimus and ciclosporin could not be used in the 4 weeks before screening. The use of non-steroidal anti-inflammatory drugs (NSAID) and oral steroids (maximum dose $10 \mathrm{mg} /$ day of prednisone or equivalent) was allowed if the dose was stable within 4 weeks before screening and kept stable throughout the study. Patients could not be included if they had active or untreated latent tuberculosis, opportunistic or other uncontrolled infections, a history of lymphoproliferative disease or malignancy in the 5 years before screening, or any other significant and uncontrolled disorder. A tuberculin skin test and chest $\mathrm{x}$-ray were performed during screening within 30 days of receiving a first infliximab infusion and/or dose of methotrexate.

The study was carried out according to the Declaration of Helsinki and conducted in accordance with the International Conference on Harmonisation Good Clinical Practice Guidelines. The study protocol was approved by the ethics committee at each of the participating study sites. All patients provided written informed consent before participating in any study-related activities.

\section{Study design}

This was a phase IIIB, randomised, prospective, open-label study conducted in 25 centres in Europe, the Middle East, South Africa and Turkey. Subjects were randomly assigned to one of two treatment arms $(1: 1)$ to receive either infliximab $5 \mathrm{mg} / \mathrm{kg}$ infusions at weeks $0,2,6$ and 14 plus methotrexate $15 \mathrm{mg} /$ week, or methotrexate $15 \mathrm{mg}$ /week alone. In both groups, methotrexate could be increased to $20 \mathrm{mg} /$ week at week 6 if improvement of $20 \%$ in the American College of Rheumatology (ACR) response criteria (ACR20) was not achieved. Assessments were performed at weeks 2, 6 and 14. The final study visit was at week 16.

\section{Outcome measures}

The primary efficacy endpoint was the proportion of subjects achieving an ACR20 response from baseline at week 16. Secondary efficacy endpoints included proportions of patients with ACR50 and ACR70 responses, 75\% improvement in the psoriasis area and severity index (PASI) in subjects whose baseline PASI was 2.5 or greater, and European League Against Rheumatism (EULAR) response. All rheumatologists were trained to perform PASI scoring. Change from baseline was investigated for the individual ACR core domains (ie, physician and patient global assessment of disease activity, patient self-reports of pain and disability, and CRP), PASI and disease activity score in 28 joints (DAS28) scores, number of digits with dactylitis, Maastricht ankylosing spondylitis enthesitis score, fatigue (visual analogue scale), duration of morning stiffness, ESR and CRP. As measures of clinical remission/minimal disease activity (MDA), the following outcomes were reported at week 16 : absence of swollen joints, tender joints, enthesitis and dactylitis; normal CRP; DAS28 remission (<2.6); PASI90 response; and published criteria for MDA. ${ }^{25}$ Axial disease was not assessed.

Safety assessments included adverse event (AE) reporting, changes in physical examination findings, clinical laboratory test results and vital signs at all visits. Investigators assessed $\mathrm{AE}$ severity and relationship to study treatment.

\section{Statistical analysis}

It was determined that a sample size of 216 (108 per treatment group) would allow detection of a $20 \%$ difference in the proportion of patients achieving an ACR20 response with 85\% power. This assessment was made assuming the use of a $\chi^{2}$ test with a significance level of 0.05 and assuming a $50 \%$ response for infliximab plus methotrexate and a $30 \%$ response for methotrexate alone. To allow for dropouts (the anticipated dropout rate was $10 \%$ ), up to 243 subjects were to be enrolled.

The intent-to-treat (ITT) population included all randomly assigned subjects who received at least one dose of study medication and had baseline as well as at least one post-baseline efficacy assessment. The efficacy-evaluable per-protocol (PP) population included all of the subjects who followed the protocol and had both baseline and week 16 efficacy data. Protocol violators were identified and the PP population decided before database lock based on a blinded review of the data. The ITT population was the primary population for the superiority analyses. As the rate of exclusion due to protocol violations exceeded $5 \%$ in each treatment group, a PP population was also analysed.

A $\chi^{2}$ test was used to compare the proportions of subjects achieving an ACR20 response at week 16. To limit bias and capture the difference in response between the infliximab plus methotrexate and methotrexate-alone groups, the study protocol specified that non-responders were patients: with missing ACR data; who withdrew due to lack of efficacy or loss of response; who received additional treatments or study medication doses outside the protocol; and who underwent surgical joint procedures. This method was chosen over non-responder imputation, which is criticised in the statistical literature for being biased and invalid even under highly restrictive assumptions about patterns of missingness, such as data that are missing completely at random. ${ }^{26} 2728$

However, for the purpose of comparison with other studies, the non-responder imputation statistics for ACR20 and PASI75 at week 16 plus MDA at each study visit are also provided here. These post-hoc analyses were requested during the journal peerreview process.

Change from baseline in the PASI score was compared between treatment groups using analysis of covariance with baseline values as the covariate. Similarly, change from baseline in DAS28 and all other secondary endpoints were compared using analysis of covariance with baseline values as the covariate, unless there were analysis methods more appropriate for the observed distribution. The difference in EULAR response between groups at each visit was assessed by testing between treatments in mean ridit scores.

The safety population included all subjects who took at least one study dose. No formal statistical testing was performed to compare the safety data between treatment groups.

\section{RESULTS \\ Patient characteristics}

As a result of the restrictive inclusion/exclusion criteria, recruitment was slow (May 2006-March 2008) and was halted at 115 subjects: 57 randomly assigned to infliximab plus methotrexate, 58 to methotrexate alone (figure 1). Four subjects in the methotrexate group withdrew consent before receiving study treatment. Thirty subjects were excluded from the PP efficacy analysis for protocol violations; of these, 10 infliximab plus methotrexate 
patients and 11 methotrexate-alone patients did not complete the study as scheduled (week 16 efficacy data missing).

At baseline, the treatment groups were generally similar and well balanced. The numerical gender difference was not statistically significant $(p=0.15)$. Subject assessment of fatigue and morning stiffness was significantly different between the two groups (tables 1 and 2).

\section{Efficacy results}

Four infliximab infusions were received by $86 \%$ (49/57) of subjects in the combination treatment arm. The mean infused dose was $389.4 \mathrm{mg}$, corresponding to approximately $5 \mathrm{mg} / \mathrm{kg}$ based on the mean body weight $(78.2 \mathrm{~kg})$. The 16 planned doses of methotrexate were received by $64.9 \%$ of infliximab plus methotrexate subjects and $79.6 \%$ of methotrexate-alone subjects. The average weekly dose of methotrexate was $14.6 \mathrm{mg}$ in the infliximab plus methotrexate group and $15.4 \mathrm{mg}$ in the methotrexatealone group. One patient in the infliximab plus methotrexate

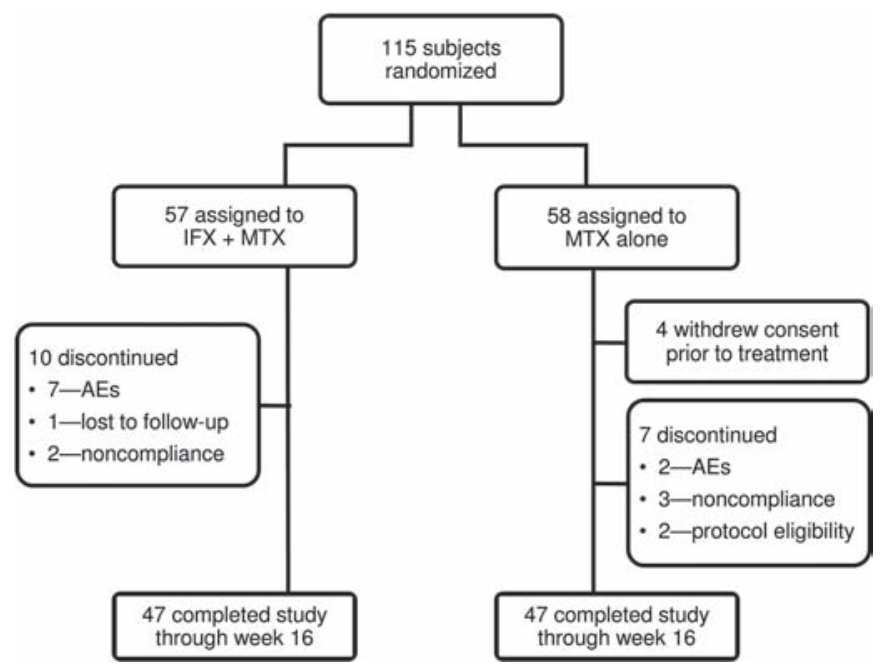

Figure 1 Disposition of study subjects. AE, adverse events; IFX, infliximab; MTX, methotrexate. group and 10 patients in the methotrexate-alone group received a dose increase to $20 \mathrm{mg}$ at week 6.

In the ITT analysis, an ACR20 response at week 16 was achieved in 44 of 51 patients $(86.3 \%)$ in the infliximab plus methotrexate group compared with 32 of 48 patients $(66.7 \%)$ in the methotrexate-alone group $(p=0.021)$. Analysis using the PP population yielded almost identical results, which were also statistically significant $(p=0.039)$. In the non-responder imputation analysis, week 16 ACR20 response rates were $78.6 \%$ in the infliximab plus methotrexate group and $59.3 \%(p=0.028)$ in the methotrexate-alone group. The difference in ACR20 response between treatment groups was statistically significant at every study visit in both the ITT and PP populations. ACR50 and ACR70 response rates at week 16 were also significantly greater in the infliximab plus methotrexate group at most study visits (figure 2).

In patients with a PASI of 2.5 or greater at baseline, a PASI75 response at week 16 was observed in 33 of 34 patients $(97.1 \%)$ receiving infliximab plus methotrexate compared with 19 of 35 patients $(54.3 \%)$ receiving methotrexate alone $(p<0.0001)$. In the non-responder imputation analysis, week 16 PASI75 response rates were $91.7 \%$ in the infliximab plus methotrexate group and $47.5 \%(p=0.00004)$ in the methotrexate-alone group. The change from baseline in PASI score was statistically significant at every time point. By week 16, the mean reduction in PASI score was $93.3 \%$ for patients treated with infliximab plus methotrexate and $67.4 \%$ for patients treated with methotrexate alone $(\mathrm{p}=0.0029)$.

The mean DAS28 at week 16 improved by $56.5 \%$ (mean change $-2.95 \pm 1.05$ ) in infliximab plus methotrexate patients compared with $29.7 \%$ (mean change $-1.51 \pm 1.31$ ) in methotrexate-alone patients $(\mathrm{p}<0.0001)$. The EULAR response at week 16 was achieved in 50 of 51 patients (98\%) receiving infliximab plus methotrexate compared with 35 of 48 patients $(72.9 \%)$ receiving methotrexate alone $(\mathrm{p}<0.0001)$.

A median reduction of two digits with dactylitis was observed at week 16 in the infliximab plus methotrexate group, while no reduction was observed in the methotrexate-alone group ( $p=0.0006)$. Between-group differences were statistically significant at all time points. A median reduction of two sites

Table 1 Subject demographics and baseline disease characteristics (ITT population)

\begin{tabular}{|c|c|c|}
\hline Subject characteristics & $\begin{array}{l}\text { Infliximab plus } \\
\text { methotrexate }(n=56)\end{array}$ & Methotrexate $(\mathrm{n}=54)^{*}$ \\
\hline Male, $\mathrm{n}(\%)$ & $27(48.2)$ & $33(61.1)$ \\
\hline Female, n (\%) & $29(51.8)$ & $21(38.9)$ \\
\hline Mean age $\pm S D$, years & $40.1 \pm 12.3$ & $42.3 \pm 10.5$ \\
\hline White, n (\%) & $52(92.9)$ & $49(90.7)$ \\
\hline Asian, $\mathrm{n}(\%)$ & $3(5.4)$ & $5(9.3)$ \\
\hline Multiracial, n (\%) & $1(1.8)$ & $0(0)$ \\
\hline Mean $\mathrm{BMI} \pm \mathrm{SD}, \mathrm{kg} / \mathrm{m}^{2}$ & $26.9 \pm 5.1$ & $28.1 \pm 5.3$ \\
\hline Mean duration of $\mathrm{PsA} \pm \mathrm{SD}$, years & $2.8 \pm 2.6$ & $3.7 \pm 2.7$ \\
\hline Mean swollen joint count $\pm S D$ & $15.1 \pm 10.1$ & $14.3 \pm 9.5$ \\
\hline Mean tender joint count $\pm S D$ & $21.1 \pm 13.3$ & $20.1 \pm 11.2$ \\
\hline Mean number of digits with dactylitis $\pm S D$ & $3.3 \pm 4.2$ & $3.1 \pm 4.2$ \\
\hline Mean number of assessment sites with enthesitis \pm SD (MASES) & $2.4 \pm 3.0$ & $2.7 \pm 2.8$ \\
\hline Mean DAS28 \pm SD & $5.16 \pm 1.1$ & $5.07 \pm 1.2$ \\
\hline Mean fatigue/tiredness score $\pm S D$, VAS rating & $55.7 \pm 22.0$ & $53.0 \pm 17.4$ \\
\hline Mean morning stiffness $\pm S D, h$ & $1.46 \pm 0.87$ & $1.13 \pm 0.58$ \\
\hline Mean $\mathrm{HAQ}-\mathrm{DI}$ score \pm SD & $1.54 \pm 0.62$ & $1.49 \pm 0.66$ \\
\hline Mean PASI \pm SD & $8.27 \pm 10.2$ & $11.62 \pm 12.5$ \\
\hline
\end{tabular}

*Except for PASI score, where $\mathrm{n}=53$

BMI, body mass index; DAS28, disease activity score in 28 joints; HAQ-DI, health assessment questionnaire-disability index; ITT, intent to treat; MASES, Maastricht ankylosing spondylitis enthesitis score; PASI, psoriasis area and severity index; PsA, psoriatic arthritis; VAS, visual analogue scale. 
Table 2 Previous medications by treatment group*

\begin{tabular}{lcc}
\hline Previous medication & $\begin{array}{l}\text { Infliximab plus } \\
\text { methotrexate } \\
\mathbf{n = 5 7}\end{array}$ & $\begin{array}{l}\text { Methotrexate } \\
\mathbf{n = 5 8}\end{array}$ \\
\hline NSAID & $5.3 \%$ & $1.7 \%$ \\
Salicylates & $1.7 \%$ & $5.3 \%$ \\
Propionic acid derivatives & $33.3 \%$ & $32.8 \%$ \\
Acetic acid derivatives & $28.1 \%$ & $19.0 \%$ \\
Oxicam derivatives & $22.8 \%$ & $15.5 \%$ \\
DMARD (sulfasalazine $\mathrm{n}=22$, chloroquine $\mathrm{n}=2$, & \\
gold $\mathrm{n}=1$ ) & $15.8 \%$ & $15.5 \%$ \\
Corticosteroids & $5.3 \%$ & $12.1 \%$ \\
Ciclosporin & $5.3 \%$ & $1.7 \%$ \\
Retinoids & & \\
\hline
\end{tabular}

* Previous medications were used by more than $5 \%$ of total patients.

DMARD, disease-modifying antirheumatic drugs; NSAID, non-steroidal anti-

inflammatory drugs.

with enthesitis was observed at week 16 in the infliximab plus methotrexate group compared with a reduction of one site in the methotrexate-alone group $(p=0.082)$. Between-group differences were not statistically significant at any time point.

The reduction from baseline in fatigue score was greater in the infliximab plus methotrexate group compared with the methotrexate-alone group at all time points. At week 16, the mean reduction from baseline was $70.8 \%$ in the infliximab plus methotrexate group compared with $44.0 \%$ in the methotrexate-alone group $(p=0.0003)$. At week 16 , the median change in the duration of morning stiffness was $-0.92 \mathrm{~h}$ with combination treatment versus $-0.50 \mathrm{~h}$ with methotrexate alone $(\mathrm{p}=0.0015)$.

Changes from baseline in all ACR core domains were significantly different between the treatments at all time points (table 3). Overall, patients receiving infliximab plus methotrexate showed more profound levels of disease suppression, as illustrated by DAS28 remission rates, absence of swollen or tender joints, normal $\mathrm{CRP}$ and PASI90 responses (figure $3 \mathrm{~A}$ ). The proportion of patients with $M D A$ at each visit was significantly greater for patients treated with combination therapy (figure $3 \mathrm{~B}$ ).

\section{Safety results}

The incidence of $\mathrm{AE}$ was higher in patients receiving infliximab plus methotrexate versus methotrexate alone. Most AE were mild or moderate. One AE in each group was considered severe: increased transaminases in the infliximab plus methotrexate group and renal colic in the methotrexate-alone group. In the infliximab plus methotrexate group, 26 of 57 subjects (45.6\%) had one or more treatment-related $\mathrm{AE}$, and in the methotrexate-alone group, 13 of 54 subjects $(24.1 \%)$ had one or more treatment-related AE. The most frequent treatment-related AE involved hepatic enzyme increases. These abnormalities occurred at similar incidence in both treatment groups and were likely to be treatment related (table 4).

Two serious AE were reported, both in the infliximab plus methotrexate group, and no deaths occurred. One subject experienced an infusion-related reaction with dyspnoea and erythema of moderate severity during the third infusion, which resolved following dexamethasone administration, but the patient was withdrawn from further treatment. Another subject was hospitalised twice for investigation of a suspected lung tumour, and infliximab was permanently discontinued following the first hospital visit. Pulmonary tuberculosis was diagnosed at the second hospital visit and anti-tuberculosis treatment was initiated. Re-evaluation of a prestudy chest x-ray revealed a lesion
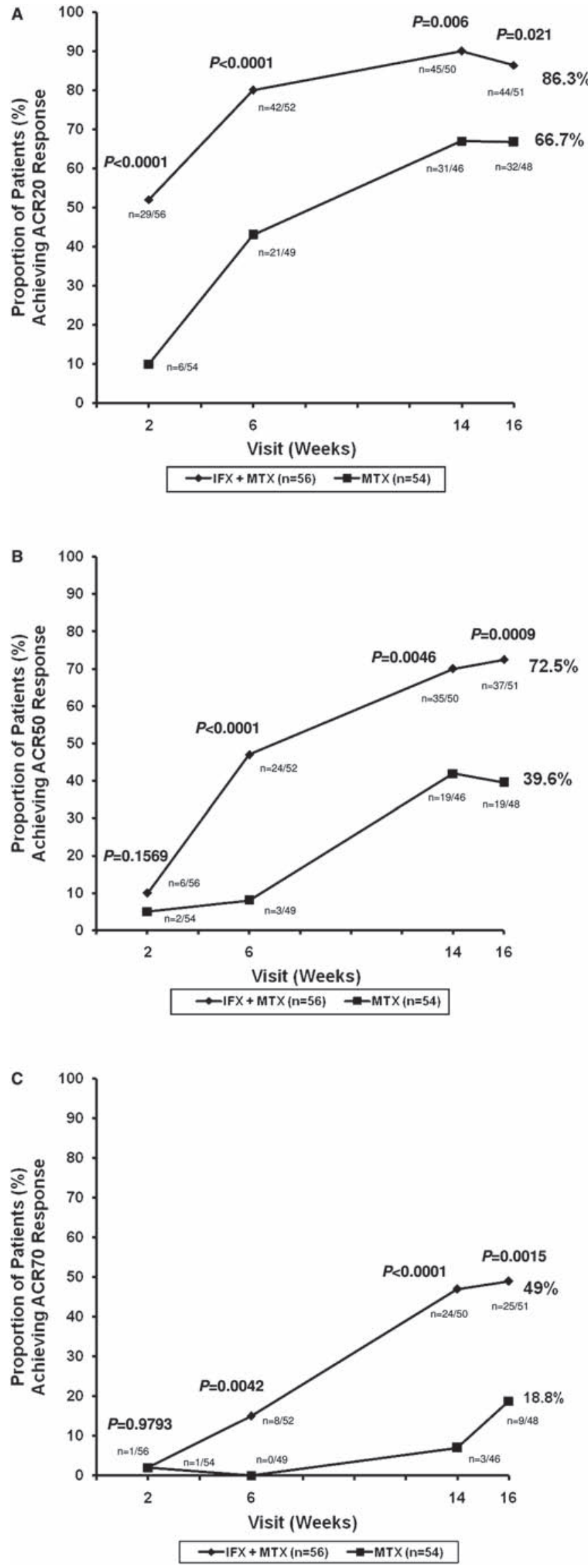

Figure 2 Proportion of patients achieving ACR20 (A), ACR50 (B) and ACR70 (C) response over time (ITT population). ACR, American College of Rheumatology; IFX, infliximab; ITT, intent to treat; MTX, methotrexate. 
Table 3 Changes from baseline in ACR core domains at week 16

\begin{tabular}{|c|c|c|c|}
\hline ACR domain & $\begin{array}{l}\text { Infliximab plus } \\
\text { methotrexate }(n=56)\end{array}$ & Methotrexate $(n=54)$ & p Value \\
\hline Swollen joint count, median change* & -11.0 & -9.0 & 0.0016 \\
\hline Tender joint count, median change ${ }^{*}$ & -14.0 & -9.5 & 0.0007 \\
\hline Subject's pain assessment, $\uparrow$ mean change $\pm S D(\mathrm{~mm})$ & $-45.8 \pm 26.4$ & $-23.1 \pm 20.0$ & $<0.0001$ \\
\hline Subject's GAD, † mean change $\pm \mathrm{SD}(\mathrm{mm})$ & $-43.0 \pm 24.2$ & $-24.1 \pm 22.7$ & $<0.0001$ \\
\hline Evaluator's $\mathrm{GAD}, \dagger$ mean change $\pm \mathrm{SD}(\mathrm{mm})$ & $-47.4 \pm 18.3$ & $-30.6 \pm 21.6$ & $<0.0001$ \\
\hline $\mathrm{HAQ}-\mathrm{DI}$, mean change $\pm \mathrm{SD}$ & $-0.99 \pm 0.72$ & $-0.56 \pm 0.72$ & 0.0041 \\
\hline CRP, median change (mg/l) & -12.0 & -5.8 & 0.0026 \\
\hline ESR, median change (s) & -12.0 & -8.0 & 0.0023 \\
\hline
\end{tabular}

†Using VAS.

ACR, American College of Rheumatology; CRP, C-reactive protein; ESR, erythrocyte sedimentation rate; GAD, global assessment of disease activity; HAO-DI, health assessment questionnaire-disability index.
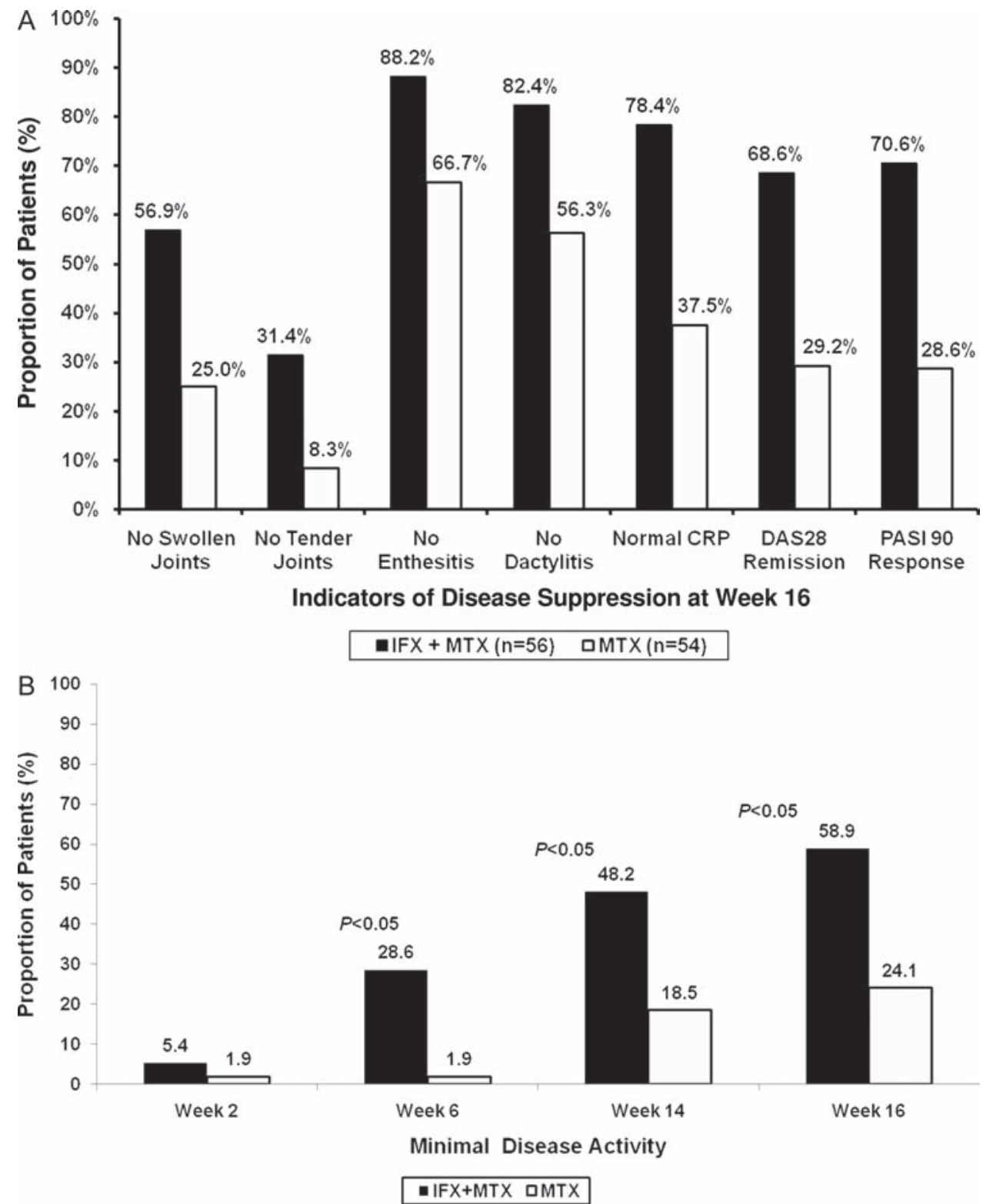

Figure 3 (A) Proportion of patients achieving indicators of profound disease suppression at week 16. All between-group differences are significant $(p<0.01)$. (B) Proportion of patients with minimal disease activity at each study visit. Between-group differences are significant at weeks 6, 14 and 16. CRP, C-reactive protein; DAS28, disease activity score in 28 joints; IFX, infliximab; MTX, methotrexate; PASI, psoriasis area and severity index. 
Table 4 Summary of adverse events

\begin{tabular}{lcc}
\hline Treatment-emergent adverse events & $\begin{array}{l}\text { Infliximab plus methotrexate } \\
(\mathbf{n = 5 7 )} \\
\text { No of subjects }(\%)\end{array}$ & $\begin{array}{c}\text { Methotrexate }(\mathbf{n}=\mathbf{5 4}) \\
\text { No of subjects } \mathbf{( \% )}\end{array}$ \\
\hline Subjects with at least one AE & $33(57.9)$ & $19(35.2)$ \\
Subjects with serious AE & $2(3.5)$ & $0(0)$ \\
Subjects with severe AE & $1(1.8)$ & $1(1.9)$ \\
Subjects with AE leading to early withdrawal & $7(12.3)$ & $2(3.7)$ \\
Subjects with treatment-related AE & $26(45.6)$ & $13(24.1)$ \\
Nasopharyngitis & $2(3.5)$ & $0(0)$ \\
Upper abdominal pain & $0(0)$ & $3(5.6)$ \\
Infusion-related reaction & $2(3.5)$ & $0(0)$ \\
Fever & $2(3.5)$ & $0(0)$ \\
Headache & $3(5.3)$ & $1(1.9)$ \\
Leucopenia & $2(3.5)$ & $0(0)$ \\
Liver enzymes: mean change from baseline to week 16 (SD) & $13.8(27.79)$ & $13.5(30.74)$ \\
ALT & $7.43(14.71)$ & $3.69(11.26)$ \\
AST & $-28.9(202.78)$ & $35.18(137.40)$ \\
GGT & $1.6(3.70)$ & $0.7(5.0)$ \\
Total bilirubin & &
\end{tabular}

that had not been noted earlier. The patient was reportedly well approximately 5 weeks after discharge.

Other AE leading to discontinuation in the infliximab plus methotrexate group included generalised oedema, pain, pyrexia, folliculitis, upper respiratory tract infection, dyspnoea and blood bilirubin increase (two patients). In the methotrexate-alone group, $\mathrm{AE}$ leading to discontinuation included diarrhoea, gastritis, nausea, vomiting and dizziness.

\section{DISCUSSION}

The IMPACT studies demonstrated that infliximab with or without methotrexate is efficacious for the treatment of active PsA in patients with an insufficient response to conventional therapy. ${ }^{21-24}$ The present open-label study compared the use of infliximab plus methotrexate with methotrexate alone in methotrexate-naive patients with PsA. A greater degree of improvement was demonstrated with infliximab plus methotrexate therapy versus methotrexate monotherapy for every measure examined. This was an open-label study; therefore these results must be confirmed in a blinded fashion.

In the first IMPACT study, the mean disease duration of PsA was 11 years or greater and all patients had failed treatment with at least one DMARD (approximately $50 \%$ had failed with two or more DMARD). ${ }^{22}$ In IMPACT 2, disease duration was approximately 8 years, $79.5 \%$ of patients had used at least one DMARD, and $68.5 \%$ of patients had used methotrexate. ${ }^{24}$ In the current study, patients had a relatively short disease duration (mean duration 2.8-3.7 years), and the majority were naive to methotrexate and most other DMARD. Observed levels of baseline disease activity and disability were similar to those observed for IMPACT patients in terms of swollen joint count, tender joint count, disease activity score, health assessment questionnaire-disability index and patient/physician global assessments. ${ }^{12}$ In this earlier treatment setting there is a strikingly larger treatment effect at week 14 on joints and skin. ACR20 response rates in the IMPACT 1 and 2 studies were $67.3 \%$ and $58.0 \%$, respectively, for infliximab (with or without methotrexate) and $11.3 \%$ and $11.0 \%$ for placebo, whereas they were greater than $80 \%$ for infliximab plus methotrexate and greater than $60 \%$ for methotrexate in the current study. PASI75 response to infliximab was $68.0 \%$ at week 16 for IMPACT 1 and $63.9 \%$ at week 14 for IMPACT 2, whereas they were less than 5\% for placebo in both studies. In the current study, the PASI responses are again significantly higher for both combination therapy and methotrexate alone.

The Group for Research and Assessment of Psoriasis and Psoriatic Arthritis (GRAPPA) treatment recommendations for PsA support the use of disease-modifying therapy in all patients with moderate or severe peripheral arthritis. ${ }^{12}$ Furthermore, the recommendations state that there is no evidence to support the use of conventional DMARD ahead of TNF inhibitors and that TNF inhibitors could be considered as first-line therapy in patients with a poor prognosis even if they have not failed treatment with a standard DMARD. ${ }^{12}$ The EULAR recommendations for the management of PsA are more conservative ${ }^{29}$ While noting that few studies have investigated the use of DMARD in PsA, they recommend that patients with active disease despite NSAID receive a DMARD 'early' (ie, a few weeks to 1 year) and methotrexate is the first choice. Upon DMARD failure and non-achievement of target low-disease activity, TNF inhibitors may be considered in patients with still-active disease.

In the present study, the high ACR20 and PASI75 response rates in methotrexate-alone patients support GRAPPA and EULAR recommendations to use methotrexate in active PsA. ${ }^{12}$ ${ }^{29}$ In light of the paucity of data for methotrexate and considering the severity of the population, this study provides important new evidence further establishing the efficacy of this DMARD in PsA. Differences between the infliximab plus methotrexate and methotrexate-alone groups were larger when more difficult to achieve outcomes such as ACR50, ACR70 and MDA were evaluated. This supports the GRAPPA recommendation to use combination therapy including an anti-TNF agent in poor-prognosis patients even if methotrexate alone has not been tried. ${ }^{12}$

Until now, there has been little evidence for any treatment providing effective relief for dactilitis and enthesitis associated with PsA. GRAPPA suggests that high-quality evidence is available only for TNF inhibitors in the treatment of severe enthesitis and dactylitis, and at present infliximab is the only TNF inhibitor recommended for the treatment of dactylitis on the basis of available evidence. ${ }^{12}$ Our study supports this recommendation and demonstrates that infliximab plus 
methotrexate is more effective than methotrexate monotherapy, although enthesitis only differed numerically between the two treatment groups.

Our study has several limitations. Recruitment was slow and, for practical reasons, was halted before attainment of the target number (216 patients). The slow pace was due to the requirement that subjects be methotrexate naive and have active PsA, as defined by the protocol. The smaller sample size is a study limitation because large studies produce narrow confidence intervals and more precise results. Significant results in a small study highlight the effect size of therapy. Some bias is introduced because of the open-label design, as many of the outcome measures were self-reported and subjective or were assessed by non-blinded evaluators. This probably had an effect on the compliance with methotrexate use and may very well have inflated the response rates in both treatment arms. Although subjective measures were used to assess many of the outcomes in this study, the objective measures, such as CRP and ESR, also significantly differed between the treatment groups. In addition, the significant differences between the two groups in remission/MDA outcomes suggest robust results despite the open-label design. It is possible that a longer study period and better compliance with treatment would have revealed increasing efficacy of methotrexate. Confirmation of methotrexate efficacy in this population via a blinded, placebo-controlled study and comparison of infliximab and methotrexate monotherapies clearly merit additional research.

Infliximab plus methotrexate treatment was generally well tolerated. Although there was a higher reported incidence of $\mathrm{AE}$ and withdrawals due to AE, this was consistent with the previously reported safety profile for infliximab, and no new safety signals were observed.

The use of infliximab plus methotrexate in methotrexatenaive patients with PsA achieved greater improvements in all clinical outcomes measured than the use of methotrexate alone. Response was more rapid with combination therapy, and it accomplished profound disease suppression in a significantly larger proportion of patients by week 16 compared with methotrexate monotherapy.

Acknowledgements Jacqueline M Mahon, MA, provided editorial assistance.

Funding Financial support for this study was provided by Schering-Plough Corporation, now Merck, Sharp \& Dohme Corporation, Whitehouse Station, New Jersey, USA.

Competing interests A Baranauskaite, H Raffayová, N Kungurov, A Kubanova, and A Venalis have nothing to disclose. LH and SS were employees of Schering-Plough Corporation, now Merck, Sharp \& Dohme Corporation (MSD), at the time this paper was written. EN has been a speaker for Roche, Schering-Plough Corporation and MSD. NV is an employee and stockholder of MSD.

Ethics approval The study protocol was approved by the ethics committee at each of the participating study sites.

\section{Patient consent Obtained.}

RESPOND investigators R Nasyrova, Central Rheumatology Institute, Moscow, Russia; E Parsik, North Estonian Regional Hospital, Tallinn, Estonia; K Otsa, East-Tallinn's Central Hospital, Tallinn, Estonia; I Butrimiene, Vilnius University Hospital, Vilnius, Lithuania; M Pileckyte, Kaunas Medical University Hospital, Kaunas, Lithuania; W Tlustochowicz, Centralny Szpital Kliniczny, Warszawa, Poland; E Kucharz, Samodzielny Publiczny Szpital, Katowice-Ochojec, Poland; Z Szekanecz, University of Debrecen, Debrecen, Hungary; G Poor, National Institute of Rheumatology and Physiotherapy, Budapest, Hungary; E Koo, Polyclinic of the Hospitaller Brothers of St John of God, Budapest, Hungary; L Hodinka, National Institute of Rheumatology and Physiotherapy, Budapest, Hungary; Z Macejova, L Pasteur's Faculty Hospital, Kosice, Slovak Republic; H Direskeneli, Marmara Universitesi Tip Fakultesi, Istanbul, Turkey; N Akkoc, Dokuz Eylul Universitesi Tip Fakultesi, Izmir, Turkey; Y Kabasakal, Ege Universitesi Tip Fakultesi, Izmir, Turkey: I Ertenli, Hacettepe Universitesi Tip Fakultesi, Ankara, Turkey; F Khatib, Arwyp
Medical Suites, Kempton Park, South Africa; EM van Duuren, Jacaranda Hospital, Pretoria, South Africa; C Spargo, Vincent Pallotti Hospital, Pinelands, South Africa; I Louw, Panorama Hospital Medical Centre, Cape Town, South Africa; C Codreanu, Centrul de Boli, Bucharest, Romania; R Ionescu, Sp Clinic Sf Maria, Bucharest, Romania; RM Chireac, Sp Clinic de Recuperare, lasi, Romania; S Rednic, Sp Clinic Judetean Cluj, Cluj, Romania; M Hammoudeh, Hamad Medical Corporation, Doha, Oatar; J Szechinski, Prywatny Gabinet Internistyczno-Reumatologiczny, Wroclaw, Poland; M Rell-Bakalarska, Przychodnia Przykliniczna, Warszawa, Poland; D Avraham, Meir MC Dermatology, Kfar Saba, Israel; D Andersone, P Stradins Clinical University Hospital, Riga, Latvia; P Keszthelyi, Bekes County Pandy Kalman Hospital, Gyula, Hungary; P Suranyi, Hajdu-Bihar County Kenezy Gyula Hospital, Debrecen, Hungary

Provenance and peer review Not commissioned; externally peer reviewed.

\section{REFERENCES}

1. Gladman DD. Psoriatic arthritis from Wright's era until today. J Rheumatol Suppl 2009;83:4-8.

2. Koo J. Population-based epidemiologic study of psoriasis with emphasis on quality of life assessment. Dermatol Clin 1996;14:485-96.

3. Shbeeb M, Uramoto KM, Gibson LE, et al. The epidemiology of psoriatic arthritis in Olmsted County, Minnesota, USA, 1982-1991. J Rheumatol 2000;27:1247-50.

4. Alenius GM, Stenberg B, Stenlund $\mathrm{H}$, et al. Inflammatory joint manifestations are prevalent in psoriasis: prevalence study of joint and axial involvement in psoriatic patients, and evaluation of a psoriatic and arthritic questionnaire. J Rheumatol 2002;29:2577-82.

5. Gladman DD, Stafford-Brady F, Chang $\mathrm{CH}$, et al. Longitudinal study of clinical and radiological progression in psoriatic arthritis. J Rheumatol 1990;17:809-12.

6. Gladman DD, Farewell VT, Nadeau C. Clinical indicators of progression in psoriatic arthritis: multivariate relative risk model. J Rheumatol 1995;22:675-9.

7. Gladman DD. Mortality in psoriatic arthritis. Clin Exp Rheumatol 2008;26 (5 Suppl 51):S62-5.

8. Borman P, Toy GG, Babaoglu S, et al. A comparative evaluation of quality of life and life satisfaction in patients with psoriatic and rheumatoid arthritis. Clin Rheumatol 2007; 26:330-4.

9. Dubertret L, Mrowietz U, Ranki A, et al. European patient perspectives on the impact of psoriasis: the EUROPSO patient membership survey. Br J Dermatol 2006; 155:729-36.

10. Gottlieb A, Korman NJ, Gordon KB, et al. Guidelines of care for the management of psoriasis and psoriatic arthritis: Section 2. Psoriatic arthritis: overview and guidelines of care for treatment with an emphasis on the biologics. J Am Acad Dermatol 2008; 58:851-64

11. Gladman DD. Psoriatic arthritis. Dermatol Ther 2009;22:40-55.

12. Ritchlin CT, Kavanaugh A, Gladman DD, et al. Treatment recommendations for psoriatic arthritis. Ann Rheum Dis 2009;68:1387-94.

13. Black RL, O'Brien WM, Vanscott EJ, et al. Methotrexate therapy in psoriatic arthritis; double-blind study on 21 patients. JAMA 1964;189:743-7.

14. Willkens RF, Williams HJ, Ward JR, et al. Randomized, double-blind, placebo controlled trial of low-dose pulse methotrexate in psoriatic arthritis. Arthritis Rheum 1984; $27: 376-81$

15. Gladman DD, Mease PJ, Ritchlin CT, et al. Adalimumab for long-term treatment of psoriatic arthritis: forty-eight week data from the adalimumab effectiveness in psoriatic arthritis trial. Arthritis Rheum 2007;56:476-88.

16. Kavanaugh A, McInnes I, Mease P, et al. Golimumab, a new human tumor necrosis factor $\alpha$ antibody, administered every four weeks as a subcutaneous injection in psoriatic arthritis: 24-week efficacy and safety results of a randomized, placebocontrolled study. Arthritis Rheum 2009;60:976-86.

17. Mease PJ, Kivitz AJ, Burch FX, et al. Etanercept treatment of psoriatic arthritis: safety, efficacy, and effect on disease progression. Arthritis Rheum 2004;50:2264-72.

18. Mease $\mathbf{P}$, Gladman DD, Ritchlin CT, et al. Adalimumab for the treatment of patients with moderately to severely active psoriatic arthritis. Arthritis Rheum 2005:52:3279-89.

19. Mease PJ, Kivitz AJ, Burch FX, et al. Continued inhibition of radiographic progression in patients with psoriatic arthritis following 2 years of treatment with etanercept. $J$ Rheumatol 2006;33:712-21.

20. Mease PJ, Ory P, Sharp JT, et al. Adalimumab for long-term treatment of psoriatic arthritis: 2-year data from the Adalimumab Effectiveness in Psoriatic Arthritis Trial (ADEPT). Ann Rheum Dis 2009;68:702-9.

21. Antoni C, Krueger GG, de Vlam K, et al. Infliximab improves signs and symptoms of psoriatic arthritis: results of the IMPACT 2 trial. Ann Rheum Dis 2005;64:1150-7.

22. Antoni CE, Kavanaugh A, Kirkham B, et al. Sustained benefits of infliximab therapy for dermatologic and articular manifestations of psoriatic arthritis: results from the infliximab multinational psoriatic arthritis controlled trial (IMPACT). Arthritis Rheum 2005;52:1227-36

23. Kavanaugh A, Antoni CE, Gladman D, et al. The Infliximab Multinational Psoriatic Arthritis Controlled Trial (IMPACT): results of radiographic analyses after 1 year. Ann Rheum Dis 2006;65:1038-43. 
24. Kavanaugh A, Krueger GG, Beutler A, et al. Infliximab maintains a high degree of clinical response in patients with active psoriatic arthritis through 1 year of treatment: results from the IMPACT 2 trial. Ann Rheum Dis 2007;66:498-505.

25. Coates LC, Fransen J, Helliwell PS. Defining minimal disease activity in psoriatic arthritis: a proposed objective target for treatment. Ann Rheum Dis 2010;69:48-53.

26. Little RJA, Rubin DB. Statistical Analysis with Missing Data, 2nd edn. Chichester: Wiley, 2002.

27. Myers WR. Handling missing data in clinical trials: an overview. Drug Information J 2000;34:525-33.
28. Dmitrienko A, Molenberghs G, Chuang-Stein C, et al. Analysis of Clinical Trials Using SAS: A Practical Guide. Cary, NC: SAS Institute Inc, 2005.

29. Gossec L, Smolen JS, Gaujoux-Viala C, et al. European League Against Rheumatism (EULAR) recommendations for the management of psoriatic arthritis with pharmacological therapies. Ann Rheum Dis 2011; Published Online First: 27 September 2011. doi:10.1136/annrheumdis-2011-200350. 